\title{
ESTUDO DA ESCOLA NOVA NO BRASIL POR MEIO DA ELABORAÇÃO DE UM JORNAL DE TURMA
}

\author{
STUDY OF PROGRESSIVE EDUCATION IN \\ BRAZIL THROUGH THE PREPARATION OF A
} CLASS NEWSPAPER

Norberto Dallabrida ${ }^{1}$

\section{RESUMO}

O presente trabalho relata e avalia o projeto "jornal de turma", que recebeu o título "A renovação pedagógica no Brasil" e foi executado no primeiro semestre de 2015 , na segunda fase do curso de licenciatura em Pedagogia da Universidade do Estado de Santa Catarina. Trata-se de uma experiência pedagógica inovadora, parte integrante da disciplina História e Educação: da Escola Nova à Redemocratização da Sociedade Brasileira. Inspirada no método ativo e colaborativo formulado pelo educador francês Célestin Freinet, essa experiência consistiu na elaboração de um conjunto de artigos sobre a renovação pedagógica no Brasil, feita por equipes formadas livremente pelas alunas da segunda fase de Pedagogia, que formaram um jornal de turma, publicado nas formas impressa e digital. A confecção do jornal escolar, portanto, constituiu-se em uma ferramenta didática criativa e instigante no estudo da Escola Nova no Brasil.

Palavras-chave: Jornal de turma. Escola Nova. Curso de Pedagogia. 


\section{INTRODUÇÃO}

No primeiro semestre de 2015, coordenei a confecção de um jornal de turma com graduandos da segunda fase do curso de Pedagogia (modalidade presencial) do Centro de Ciências Humanas e da Educação (FAED) da Universidade do Estado de Santa Catarina (UDESC). Essa ferramenta didática é um desdobramento de experiências inovadoras que eu venho colocando em prática como professor da disciplina História e Educação, com a implantação, a partir de 2011, da nova matriz curricular do curso de licenciatura em Pedagogia. Em realidade, as minhas inquietações sobre os conteúdos que devem ser ministrados na disciplina de História da Educação na graduação em Pedagogia emergem das minhas práticas pedagógicas e das prescrições da atual matriz curricular do curso de Pedagogia. Assim, no segundo semestre de 2011, iniciei a elaboração de roteiros para cada unidade do plano de ensino, sendo eles constituídos pelas seguintes partes: questões, leituras imprescindíveis, cronograma e leituras de aprofundamento. Esses roteiros de unidades programáticas procuravam trabalhar com questões que demandariam pesquisa bibliográfica por parte dos alunos, bem como consultas ao professor.

O meu estágio pós-doutoral, realizado no primeiro semestre de 2013, na Universidad de Alcalá de Henares, teve como questão central o movimento da Escola Nova na Espanha e no espaço europeu. Como professor de História da Educação motivado a incrementar as minhas aulas na licenciatura em Pedagogia, durante esse estágio, mantive contato com a experiência didática realizada pela Profa. Drá. Sara Ramos 
Zamora na disciplina Historia y Corrientes Internacionales de la Educación, ministrada no curso de licenciatura em Pedagogia da Faculdade de Educação da Universidade Complutense de Madrid. O foco dessa disciplina é a renovação pedagógica, durante o século XX, em escala global e na Espanha, sendo o conteúdo dividido nas seguintes partes: "O movimento da Escola Nova" (Dewey, Montessori, Decroly, Freinet, dentre outros), "Educação socialista" (Makarenko), "Movimento antiautoritário em Pedagogia" (Ferrer i Guardia, Neill e Steiner), "Teorias educativas personalistas" (Paulo Freire e Lorenzo Milani) e "Crítica à instituição escolar" (Paul Goodman e Ivan Illich). Para operacionalizar esses conteúdos, a professora dessa disciplina elaborou uma apostila intitulada Herramienta Didáctica Documental ["Ferramenta didática documental", em português] (ZAMORA, 2012), que contém uma apresentação de cada unidade e reproduz excertos de autores/as a serem trabalhados com os alunos. De outra parte, desde 2011, o fechamento da disciplina é feito por meio de um "seminário pedagógico", em que os alunos apresentam, em equipes, os trabalhos pesquisados ao longo do ano letivo. Essa experiência diferenciada tem afinidades com a minha prática de elaborar roteiros de estudos e me estimulou a planejar uma atividade em equipe com os meus alunos.

Pois bem, em 2014, além de continuar a trabalhar com roteiros de estudos, planejei a elaboração de um jornal de turma, viabilizado por meio da parceria entre o curso de Pedagogia da UDESC e o Jornal da Educação - único jornal segmentado da área da educação no estado de Santa Catarina e um dos poucos no Brasil, com periodicidade mensal e divulgado nas formas escrita e digital (www.jornaldaeducacao.inf.br). Em boa 
medida, essa parceria foi viabilizada pelo fato de eu assinar, há mais de 12 anos, a coluna "Histórias da Educação" no Jornal da Educação, que procura fazer uma conexão entre o universo acadêmico e os sistemas públicos de educação e as redes de escolas privadas. A elaboração de jornal como estratégia de aprendizagem foi criada e desenvolvida pelo educador francês Célestin Freinet, que introduziu a imprensa na cultura escolar, a partir da década de 1920, para estimular os alunos. Assim, no segundo semestre de 2014 , a proposta da elaboração de um jornal de turma foi concretizada com a segunda fase do curso de Pedagogia da UDESC, sendo intitulado "A renovação pedagógica no século XX". Nesse ensaio pioneiro, o foco foi colocado sobre experiências pedagógicas renovadoras em nível mundial, contemplando, em primeiro lugar, as diferentes matrizes dos movimentos da Escola Nova e antiautoritário em Pedagogia. No primeiro semestre de 2015 , elaborei, com a segunda fase do curso de Pedagogia da UDESC, um segundo jornal de turma, cujo mote foi a renovação pedagógica no Brasil, objeto deste trabalho. A elaboração do jornal de turma, portanto, procurou estimular os alunos a buscarem conhecimentos novos sobre a renovação pedagógica no Brasil.

\section{CONTEXTO EM QUE O TRABALHO ESTÁ INSERIDO}

Na nova matriz curricular do curso de licenciatura em Pedagogia da UDESC, implantada em 2011, os conteúdos de História da Educação são "encapsulados" em duas disciplinas: História e Educação: da Constituição da Escola Moderna à Primeira República (primeira fase) e História e Educação: da Escola Nova à Redemocratização da Sociedade Brasileira (segunda fase) (UDESC, 2010, p. 9). Na segunda disciplina, o tema dominante é 
o movimento da Escola Nova, que se coloca, no início do século $\mathrm{XX}$, tanto no espaço europeu, com as experiências fundadoras de Maria Montessori e Ovídio Decroly, como nos Estados Unidos, tendo como trabalho de vanguarda a escola elementar da Universidade de Chicago, coordenada por John Dewey. E se articula, a partir de 1921, com a criação da Liga Internacional da Educação Nova, passando a ter ampla divulgação por meio da criação de revistas e de congressos. No Brasil, a partir da década de 1920, algumas matrizes do movimento da Escola Nova passam a circular e a ser apropriadas por educadores nacionais, com destaque para Lourenço Filho, Fernando de Azevedo e Anísio Teixeira. Nessa direção, a ementa dessa disciplina contempla o estudo do "Manifesto dos pioneiros da Educação Nova", experiência educacional no Distrito Federal na primeira metade da década de 1930, liderada por Anísio Teixeira, e o florescimento do movimento escolanovista a partir dos anos 1950, contido pelo golpe militar de 1964.

A partir dessa prescrição, no primeiro semestre deste ano, depois de uma unidade introdutória, a disciplina História e Educação: da Escola Nova à Redemocratização da Sociedade Brasileira desenvolveu, na segunda unidade, o título "O movimento da Escola Nova", que procurou destacar a emergência dessa nova onda pedagógica em nível global e sublinhar a existência das diferentes matrizes desse movimento, dentre as quais, foram trabalhadas, de modo aprofundado, as experiências coordenadas por John Dewey, Maria Montessori, Ovídio Decroly, Célestin Freinet. Tendo como referência essa atmosfera pedagógica, a terceira unidade colocou o foco sobre as primeiras circulações e a apropriação do movimento escolanovista no Brasil, que desaguaram na 
publicação do "Manifesto dos pioneiros da Educação Nova", em 1932, provocando intensos debates na década de 1930 entre os "pioneiros" e católicos. Depois da contração durante a ditadura estado-novista, a Escola Nova floresceu a partir de meados dos anos 1940, quando foram realizadas experiências inovadoras, como a Escola Parque, idealizada por Anísio Teixeira e concretizada pela irmã dele, Carmen Teixeira, o uso efetivo do método Montessori-Lubienka e as escolas experimentais. De outra parte, entre o final dos anos 1950 e o golpe militar de 1964, essa disciplina coloca em relevo o trabalho escolanovista desenvolvido por Paulo Freire na educação de jovens e adultos, que ganharia ampla disseminação e uso social em vários países do mundo. Enfim, na última unidade, que abordou as escolas alternativas, as matrizes mais não diretivas do movimento escolanovista voltaram a ser relidas tanto no mundo como no Brasil.

É a partir do eixo transversalizador da circulação e da apropriação do movimento da Escola Nova no Brasil que foi pensada a elaboração do projeto jornal de turma na disciplina História e Educação: da Escola Nova à Redemocratização da Sociedade Brasileira, que integra a segunda fase do curso de Pedagogia da UDESC, no primeiro semestre de 2015. Trata-se de uma turma constituída somente por mulheres, que iniciou o semestre com 40 alunas e o terminou com o número de 34 . As alunas que efetivamente cursaram a disciplina, divididas em equipes, participaram da elaboração do jornal de turma, que teve a colaboração também de estudantes de professores do Programa de Pós-Graduação da UDESC e de outras universidades que estão estudando momentos de renovação pedagógica no Brasil - conforme será detalhado abaixo. $\mathrm{O}$ 
planejamento, a elaboração e o lançamento do jornal de turma ocorreram entre os meses de março e maio de 2015 - durante boa parte do semestre letivo.

\section{CONTEÚDOS CURRICULARES ABORDADOS E PROCEDIMENTOS DIDÁTICOS}

O projeto jornal de turma "A Renovação Pedagógica no Brasil" colocou o foco sobre processos e experiências apropriadas nas matrizes do movimento escolanovista, que atravessaram o século XX. Não por acaso, a apresentação do jornal, escrita por mim, é intitulada "A educação brasileira na clave da Escola Nova". Para tanto, considera-se que as matrizes pedagógicas são produzidas em locais e momentos históricos determinados, circulam no espaço transnacional e são apropriadas por agentes sociais específicos (CARVALHO, 2003). O conceito de apropriação é compreendido na perspectiva de Chartier $(1990,1992)$, que considera que os bens culturais são usados de forma diferente, de modo que a recepção é realizada com criatividade, por meio de resistências, ressignificações e arranjos. Nesse sentido, o foco é colocado sobre "os usos diferenciados e opostos dos mesmos bens culturais, dos mesmos textos e das mesmas ideias" (CHARTIER, 1992, p. 233). De outra parte, explorou o método Paulo Freire, que foi gestado no Brasil a partir do final dos anos 1950, mas que vem sendo apropriado em projetos educativos de vários países do mundo, convertendo-se na "Pedagogia Made in Brasil" (GHIRALDELLI JÚNIOR, 2005, p. 106). As experiências inovadoras realizadas no Brasil são, portanto, contextualizadas em nível transnacional, de sorte a dar visibilidades aos fluxos pedagógicos entrecruzados. 
Na confecção do jornal de turma, houve estímulo às equipes de alunas no sentido de escolherem conteúdos relacionados a ideias pedagógicas e/ou processos/experiências educativas de caráter renovador, desde as primeiras décadas do século XX até os dias atuais/tempo presente. Dessa forma, foram escolhidos os seguintes educadores/as inovadores/as: Armanda Álvaro Alberto, abordada em "Feminista, comunista e... Educadora!", Cecília Meireles em "Cecília Meireles e o futuro do Brasil pela educação", Fernando de Azevedo em "O pensamento educacional de Fernando de Azevedo", Anísio Teixeira em "Anísio Teixeira: trajetórias e conquistas" e em "O INEP sob a liderança de Anísio Teixeira e a renovação pedagógica (19521964)" e Paulo Freire em "O legado de Paulo Freire em debate: resistências às críticas". Também foram elegidas as seguintes experiências educacionais renovadoras no Brasil, cujos títulos dos artigos são: "Pedagogia anarquista no Brasil: A Escola Moderna N. 1" (sobre uma filial da Escola Moderna de Ferrer e Guardia, em São Paulo, na década de 1910), "Mate com angu" (sobre a Escola Regional de Meriti, fundada e dirigida por Armanda Álvaro Alberto, em 1921, que tinha inspiração montessoriana), "Escola Parque: uma experiência pública e inovadora" (sobre a escola pública criada por Anísio Teixeira em 1951, que foi visitada e referenciada pela UNESCO), "Escolas alternativas: um lugar para viver as infâncias" (sobre as duas primeiras escolas alternativas de Florianópolis) e "Levando a sério a menor idade" (que lança um olhar histórico sobre as creches, dando visibilidade à Creche Hassis, considerada um modelo em sustentabilidade). Ademais, os artigos intitulados "John Dewey e a formação de professores no início do século XX", que aborda a circulação das ideias deweyanas em uma revista de uma escola normal paulista, "O documento que 
fundou a educação pública", sobre o texto fundador da renovação educacional no Brasil, publicado em 1932, e "Os primeiros passos da educação de adultos", sobre a primeira campanha de alfabetização de adultos promovida pelo estado brasileiro, a partir de 1947, sob a batuta de Lourenço Filho.

Embora os chamados "três cardeais da Escola Nova no Brasil" (Lourenço Filho, Fernando de Azevedo e Anísio Teixeira) tenham sido abordados e com justiça, o jornal "A Renovação Pedagógica no Brasil" enfatizou a intervenção de mulheres no campo educacional. O destaque foi dado para Armanda Álvaro Alberto, que atuou em agremiações de caráter educativo, como a Associação Brasileira de Educação (ABE), a Aliança Nacional contra o Analfabetismo e a União Feminina do Brasil. Todavia, Armanda é celebrada, sobremaneira, devido à criação e à administração da Escola Regional de Meriti, uma experiência educativa inovadora, inspirada nas ideias montessorianas e realizada em uma vila operária do Rio de Janeiro. Assim, no início da década de 1960, a Associação Brasileira de Educação afirmou: "Dra. Armanda Álvaro Alberto pode ser comparada sem favor, no plano brasileiro, às maiores figuras da pedagogia brasileira e cognominada, sem exagero, a Montessori brasileira" (ABE apud MIGNOT, 2010, p. 98). Nos dias que correm, a relevância dada a Anísio Teixeira como gestor cosmopolita e criativo de sistemas públicos de ensino, com destaque para a atuação como conselheiro da UNESCO, a criação da Escola Parque, em Salvador, e a instituição do Centro Brasileiro de Pesquisas Educacionais (CBPE), é, definitivamente, muito pertinente. E o artigo sobre Paulo Freire é instigante na medida em que toma como mote uma faixa das manifestações de 15 de março de 2015 que dizia "Chega de doutrinação marxista 
- Basta de Paulo Freire" e faz uma defesa sobre as ideias do educador brasileiro mais conhecido, divulgado e apropriado no mundo.

O jornal de turma objeto deste trabalho foi inspirado no educador francês Célestin Freinet, o pioneiro da imprensa escolar e um dos precursores do trabalho cooperativo (FREINET, 1974). O método freinetiano parte da elaboração de textos livres - a partir das "aulas-passeio" e/ou de leituras em sala de aula -, que são corrigidos coletivamente pelos alunos e pelo professor. Esses textos produzidos pelos alunos são impressos e enviados para outras escolas, na expectativa da realização de trocas recíprocas de conhecimentos escolares. Inspirado na experiência freinetiana, o jornal começou a ser elaborado quando o professor apresentou uma série de experiências pedagógicas renovadoras realizadas no Brasil, desde o início do século XX até o presente, para que as alunas, organizadas em equipes, fizessem as escolhas. Feitas as eleições dos temas, as equipes passaram a realizar o trabalho de pesquisa na internet, na Biblioteca Central da UDESC e em outros acervos, sob a minha supervisão. A partir de um cronograma previamente acordado, as equipes enviaram para o professor a primeira versão do artigo, que foi lido e avaliado tanto com relação à forma (houve o estabelecimento de regras formais: tamanho do texto, configuração da imagem, normalização, dentre outros) quanto com relação ao conteúdo. Posteriormente, foi solicitada às equipes uma versão definitiva do artigo, precedido de outras versões. A versão final do artigo ainda foi avaliada por mim e pela editora-chefe do Jornal da Educação, Maria Goreti Gomes. 
É importante assinalar que, apesar de a disciplina História e Educação: da Escola Nova à Redemocratização da Sociedade Brasileira, ministrada por mim, no primeiro semestre de 2015, ser ofertada na modalidade presencial, ela usou a ferramenta Moodle, praticando hibridismo entre as modalidades de ensino presencial e a distância - blended learning. O Moodle que eu utilizei na disciplina é gerenciado pelo Centro de Ensino a Distância (CEAD) da UDESC, universidade à qual eu estou vinculado como professor efetivo. Dessa forma, cada unidade do plano de ensino tornou-se um tópico no Moodle, contendo inicialmente os roteiros de estudos - conforme citado acima -, mas também textos, imagens, vídeos, atividades semanas, etc. Para se gerenciar a elaboração do jornal de turma a distância, foi criado, no Moodle da minha disciplina, um tópico chamado "Jornal de turma", contendo orientações diversas para toda a turma da segunda fase e/ou recados específicos para equipe/s ou alunas em especial. Essa interface a distância, por meio do Moodle, mostrou-se mais eficiente que o ensino presencial, porque os jovens trabalham muito bem online e, sobretudo, pelo fato de eu conseguir me comunicar, efetivamente, com todas as alunas. Ou seja, nas aulas presenciais, geralmente há estudantes ausentes que, se não houvesse uma ferramenta virtual para toda a turma, ficariam desinformadas. No conjunto da disciplina e, particularmente, na elaboração do jornal de turma, o Moodle mostrou-se uma ferramenta instigante e eficaz, indicando que o blended learning é uma tendência que se afirma cada vez mais no ensino nos dias que correm.

A versão impressa do jornal de turma "A Renovação Pedagógica no Brasil" tornou-se um caderno especial do número 286 do Jornal da Educação, publicado em maio de 2015. O lançamento 
foi realizado no dia 3 de junho de 2015, durante as aulas presenciais, parte integrante de uma matéria produzida pela Assessoria de Comunicação da UDESC/FAED (HOMMERDING, 2015). O jornal de turma foi distribuído em nível interno, para as turmas do curso de licenciatura em Pedagogia da UDESC, para as/os docentes do Centro de Ciências Humanas e da Educação e do Centro de Ensino a Distância (CEAD) da UDESC, bem como para os professores da Universidade Federal de Santa Catarina (Florianópolis - SC) e da Universidade de São José (São José - SC). A tiragem de 5.000 exemplares do Jornal da Educação circulou por boa parte das escolas das redes públicas estadual e municipais, bem como em escolas privadas. No entanto, a versão digital desse jornal (http://www.faed.udesc. br/arquivos/id_submenu/1986/jornal_da_educacao_286 caderno_udes_renovacao_pedagogica_brasil.pdf) foi divulgada, via e-mail, de forma muito mais rápida e ampla em Santa Catarina, no Brasil e no exterior - particularmente na Espanha, em Portugal e em países latino-americanos.

Ao apresentar o projeto do jornal de turma para a segunda fase do curso de licenciatura em Pedagogia da UDESC, foram explicitados os procedimentos de avaliação, que consistiam em considerar tanto o processo como o produto. Na primeira dimensão, considerou-se o trabalho das equipes em sala de aula no horário presencial e extraclasse, incluindo a troca de comunicações por meio do Moodle. Nesse processo, consideraram-se o modo como as equipes decidiram a escolha do tema do artigo para o jornal da turma e, sobremaneira, as estratégias que elas criaram para realizar a pesquisa tanto na internet como em bibliotecas. Verificou-se que várias equipes desdobraram a pesquisa e enriqueceram a consulta a textos, 
imagens e vídeos, enquanto outras (poucas) acomodaramse na leitura de textos disponibilizados pelo professor. Com relação ao produto - o artigo para o jornal da turma -, foi comunicado às equipes que seriam avaliados aspectos referentes à apresentação formal e ao conteúdo. No tocante à forma, foram apreciados os seguintes aspectos: título do artigo, correção e fluência textual, divisão tripartite do texto (introdução/desenvolvimento/conclusão), observância das normas da ABNT - para aqueles textos que usaram referências - e escolha da/s imagem/s associadas ao texto. Com relação ao conteúdo, foi levada em conta a consistência da abordagem do tema escolhido, atentando-se para o tratamento de elementos centrais. Enfim, é indispensável registrar que a avaliação qualitativa (comentários) e quantitativa (nota entre zero e 10, conforme a legislação em vigor na UDESC) do artigo não foi dada somente com relação à versão final publicada no jornal da turma, mas também com respeito à primeira e às outras versões, considerando-se a superação de limites das equipes tanto em forma como no tocante ao conteúdo.

\section{CONCLUSÕES}

Acredito que o projeto relatado neste trabalho contribuiu, efetivamente, para o meu desenvolvimento profissional na condição de professor de História da Educação no curso de licenciatura em Pedagogia da UDESC. Acredito que, na questão da seleção dos conteúdos na disciplina História da Educação, à luz da nova matriz curricular em vigor para os cursos de licenciatura em Pedagogia no Brasil, é necessário tonificar os estudos sobre o movimento da Escola Nova, devido ao fato de as matrizes do movimento terem se espraiado até o tempo 
presente (NÓVOA, 2011). Assim, a história que eu venho defendendo em textos e ensinando em sala de aula procura enfatizar a releitura das ideias em processo de circulação transnacional e de apropriações específicas em diferentes escalas, particularmente aquelas em nível de redes escolares e mesmo de escolas. Essas minhas ideias têm afinidades, por exemplo, com a obra Quinze pedagogos (HOUSSAYE, 2013), lançada recentemente no Brasil sob a revisão técnica de Nilda Alves, que chama a atenção para o esquecimento com relação às matrizes pedagógicas renovadoras, em boa medida, devido ao poder do tecnicismo imposto desde a década de 1960, e à busca de raízes pedagógica nacionais, especialmente em torno das ideias de Paulo Freire.

De outra parte, a partir de 2011, com a implantação do novo currículo do curso de licenciatura em Pedagogia na UDESC, eu venho envidando esforços no sentido de dinamizar as minhas aulas de História da Educação, por meio da utilização da ferramenta Moodle, do uso de pequenos documentários que chamem a atenção para os conteúdos programáticos, de exercícios comparativos entre diferentes modelos escolares, de visitas a museus escolares e da elaboração de jornal de turma em equipes. Esta última estratégia didática foi usada, por mim, pela primeira vez, no segundo semestre de 2014, quando foi elaborado um jornal de turma sobre as matrizes da renovação pedagógica (escolanovista) durante século $\mathrm{XX}$ (John Dewey, Maria Montessori, Ovídio Decroly, Célestin Freinet, dentre outros). No primeiro semestre de 2015, o jornal de turma colocou o foco sobre "a renovação pedagógica no Brasil" - objeto deste trabalho. À medida que esses jornais circulam e são enviados para secretarias da educação e escolas 
públicas e privadas, contribuem para fazer conexões entre o mundo acadêmico e mundo escolar. Estou convencido de que a elaboração de jornal de turma em equipes é uma ferramenta didática eficaz para estimular os estudantes à pesquisa educacional.

Acredito que, para a formação das alunas, a experiência de produção coletiva de um jornal escolar sobre a renovação pedagógica no Brasil foi estimulante. Por um lado, por causa da proposta de trabalho ativo e colaborativo, inspirado no método freinetiano, que instigou as equipes a se organizarem para escolher o tema do artigo, realizar a pesquisa, elaborar o texto e selecionar imagens. Nesse ritmo, a grande maioria motivouse para o trabalho coletivo para produzir conhecimento novo, o que demanda capacidade de divisão/execução de tarefas e autogoverno. De outra parte, o tema escolhido para o jornal de turma mobilizou as alunas no sentido de estudar autores, processos e experiências renovadoras na história da educação brasileira, particularmente inspiradas em matrizes pedagógicas do movimento escolanovista. O foco no Brasil - mas sempre em conexão com o mundo - foi interessante para que as alunas percebessem a existência de experiências educativas vanguardistas e ricas no nosso país, além do Método Paulo Freire, como a Escola Regional de Meriti e a Escola Parque. Ou seja, geralmente, os alunos de Pedagogia encantamse com experiências internacionais, como a de Summerhill (Inglaterra) e, atualmente, a da Escola da Ponte (Portugal) fato importante para a formação pedagógica deles -, mas não conhecem e, por isso, não estudam experiências educativas brasileiras instigantes, que, às vezes, são mais valorizadas no exterior. Ademais, mais da metade das alunas fez um ensaio 
individual na minha disciplina sobre uma questão do tema do artigo do jornal de turma, indicando que a elaboração do jornal suscitou interesse em se aprofundar a pesquisa.

Enfim, avalio que os demais participantes do projeto do jornal de turma, como uma mestranda e um doutorando do Programa de Pós-Graduação da UDESC e alunos e professores de outras universidades, tiveram uma atuação apropriada. Como as equipes de trabalhos da segunda fase do curso de Pedagogia da UDESC escolheram os temas sobre a renovação pedagógica no Brasil para os artigos, alguns autores, processos e experiências ficaram em descoberto. Como organizador do jornal, inicialmente busquei colaboradores entre alunos vinculados à pós-graduação em Educação da UDESC e, posteriormente, agreguei especialistas de outras universidades que investigam questões que interessavam à proposta do jornal de turma. Essas parcerias internas e externas, buscadas depois de as equipes terem escolhido os temas, contribuíram para se construir um mosaico consistente da renovação pedagógica no Brasil.

\section{REFERÊNCIAS}

CARVALHO, Marta Chagas. A escola e a República e outros ensaios. Bragança Paulista: EDUSF, 2003.

CHARTIER, Roger. A história cultural: entre práticas e representações. Lisboa: DIFEL, 1990.

CHARTIER, Roger. VI. Textos, impressões, leituras. In: HUNT, Lynn (Org.). A nova história cultural. São Paulo: Martins Fontes, 1992. p. 211-238. 
FREINET, Célestin. O jornal escolar. Lisboa: Editorial Estampa, 1974.

GHIRALDELLI JUNIOR, Paulo. História da Educação Brasileira. São Paulo: Cortez, 2006.

HOUSSAYE, Jean (Org.). Quinze pedagogos: textos selecionados. Petrópolis, RJ: De Petrus et Alii, 2013.

JORNAL da Educação. Joinville (SC), mar.-mai. 2015. Disponível em: <http://www.faed.udesc.br/arquivos/ id_submenu/1986/jornal_da_educacao_286_caderno_ udes_renovacao_pedagogica_brasil.pdf>. Acesso em: 24 jul. 2015.

MIGNOT, Ana Chrystina Venancio. Armanda Álvaro Alberto. Recife: Fundação Joaquim Nabuco, Editora Massangana, 2010.

NÓVOA, António. O regresso dos professores. Lisboa: Edição do Autor, 2011.

UDESC. Centro de Ciências Humanas e da Educação. Projeto Político Pedagógico do Curso de Licenciatura em Pedagogia. Florianópolis, 2010. Disponível em: <http://www.faed.udesc.br/arquivos/id_submenu/495/ pedagogia_2012.pdf>. Acesso em: 20 abr. 2015.

ZAMORA, Sara Ramos. Historia y corrientes internacionales de la Educación: grado Pedagogía - Herramienta Didáctica Documental - Guía del Alumno/a - Curso Académico 2012-2013. Madrid: Univerdad Complutense de Madrid, 2012. 


\section{ABSTRACT}

The present study describes and evaluates the class newspaper project "Pedagogical Revival in Brazil", published in the first term of 2015 by first-year students of pedagogy at Universidade de Santa Catarina - UDESC. The newspaper consists of an innovative pedagogical proposal as part of the discipline "History and Education: from Progressive Education to Brazilian Society`s re-democratization". Inspired by French educator Célestin Freinet's active and collaborative approach, the experience consisted of the preparation of several articles on the Pedagogical Revival in Brazil, written by some freelyformed groups of first-year students of pedagogy, who developed a class newspaper, published both in hard copies and digital format. The class newspaper's production process was, therefore, a creative and exciting didactic resource in the study of the Progressive Education in Brazil.

Keywords: Class Newspaper. Progressive Education. Pedagogy.

\section{Norberto Dallabrida}

Doutor em História pela Universidade de São Paulo (USP) e professor do curso de Pedagogia e do Programa de PósGraduação em Educação na Universidade do Estado de Santa Catarina (UDESC). Realiza pesquisa científica na área de História da Educação, especialmente sobre a renovação do ensino secundário e o movimento da Escola Nova. Bolsista de Produtividade do CNPq.

norbertodallabrida@gmail.com 